\title{
INIERESPACQ
}

\section{RUA DO LAZER NO CENTRO DE GOIÂNIA: uma análise a partir do conceito de lugar}

\author{
RUA DO LAZER IN THE CENTER OF GOIÂNIA: an analysis based on the \\ concept of place
}
RUA DO LAZER EN EL CENTRO DE GOIÂNIA: un análisis basado en el concepto de lugar

\section{Josiane Silva de Oliveira}

Mestranda em Geografia pela Universidade Federal de Goiás - UFG. Bolsista FAPEMA. Membro do Núcleo de Ensino e Pesquisas em Educação Geográfica - NEPEG.

josieaveiro5@gmail.com / http://orcid.org/0000-0003-3595-1976

\section{Juliana Mendes de Morais}

Mestranda em Geografia pela Universidade Federal de Goiás - UFG. Membro do Núcleo de Ensino e Pesquisas em Educação Geográfica - NEPEG. julimendesdemorais@outlook.com / http://orcid.org/0000-0002-8537-8568

\section{Marcos Pedro da Silva}

Doutorando em Geografia pela Universidade Federal de Goiás - UFG. Membro do Núcleo de Ensino e Pesquisas em Educação Geográfica - NEPEG.

marcos.prof.geoambiental@gmail.com / http:/ / orcid.org/0000-0002-2084-9234

Recebido: 26/03/2020; Aceito: 12/02/2021; Publicado: 22/08/2021.

\section{RESUMO}

A proposta deste artigo almeja esboçar uma análise da Rua do Lazer a partir do conceito de lugar por meio das narrativas dos sujeitos que ali expressam seu cotidiano, colocando a rua como lugar de significado e de diferentes dimensões enquanto movimento da vida, possível de ser apreendido pela memória. O caminho do passado dessa rua, por intermédio da história oral, torna-se um elemento primordial para entender seu sentido na vida dos sujeitos. Nessa perspectiva, a pesquisa foi realizada com comerciantes que atuam em sua maioria desde a década de 1960 e que ali persistiram apesar das diferentes reconfigurações ocorridas ao longo do tempo. Com aporte da história oral, a pesquisa buscou compreender o significado de lugar atribuído à Rua do Lazer por esses comerciantes e suas perspectivas em relação ao processo de revitalização, ocorrido no decorrer do ano de 2019, por meio de uma parceria público-privada. Como caminho metodológico, incluiu-se a abordagem qualitativa, pesquisa bibliográfica, documental e de campo, com a utilização de entrevistas realizadas in loco. Dessa forma, os dados coletados apontam a relação estabelecida entre a Rua do Lazer e os sujeitos que nela vivem, bem como para as mudanças que a configuram atualmente.

Palavras-chave: Lugar; Significado; Memórias; Rua do Lazer - GO.

\section{ABSTRACT}

The purpose of this article aims to outline an analysis of Rua do Lazer from the concept of place through the narratives of the subjects who express their daily life there, placing the street as a place of meaning and of different dimensions as a movement of life, possible to be apprehended by 
memory. The path of the past of this street, through oral history, becomes a primordial element to understand its meaning in the subjects' lives. In this perspective, the research was carried out with traders who have been operating mostly since the 1960s and who have persisted with the different reconfigurations that occurred over time. With the contribution of oral history, the research sought to understand the meaning of place attributed to Rua do Lazer by these sellers and their perspectives in relation to the revitalization process, which occurred during the year 2019, through a public-private partnership. As a methodological approach, a qualitative approach, bibliographic, documentary and field research was included, with the use of on-the-spot interviews. Thus, the data collected point us to the relationship that is established between Rua do Lazer and the subjects who live on it, as well as to the changes that currently configure it.

Keywords: Place; Meaning; Memoirs; Rua do Lazer - GO.

\section{RESUMEN}

El propósito de este artículo tiene como objetivo esbozar un análisis de la Rua do Lazer desde el concepto de lugar a través de las narraciones de los sujetos que expresan su vida cotidiana allí, colocando la calle como un lugar de significado y de diferentes dimensiones como un movimiento de la vida, que puede ser aprehendido. a través de la memoria. El camino del pasado de esta calle, a través de la historia oral, se convierte en un elemento primordial para comprender su significado en la vida de los sujetos. En esta perspectiva, la investigación se llevó a cabo con comerciantes que han estado operando principalmente desde la década de 1960 y que allí han persistido pese a las diferentes reconfiguraciones que ocurrieron con el tiempo. Con el apoyo de la historia oral, la investigación buscó comprender el significado de lugar atribuido a la Rua do Lazer por estos comerciantes y sus perspectivas con respecto al proceso de revitalización, que se produjo durante el año 2019, a través de una asociación público-privada. Como enfoque metodológico, se incluyó un enfoque cualitativo, bibliográfico, documental y de investigación de campo, con el uso de entrevistas sobre el terreno. Por lo tanto, los datos recopilados nos señalan la relación establecida entre la Rua do Lazer y los sujetos que viven en ella, así como los cambios que actualmente la configuran.

Palabras clave: Lugar; Significado; Recuerdos; Rua do Lazer - GO.

\section{INTRODUÇÃO}

Este artigo tem como objetivo esboçar uma análise da Rua do Lazer a partir do conceito de lugar, utilizando, para isso, as narrativas dos sujeitos que ali expressam seu cotidiano. Para tanto, a pesquisa procurou ouvir os entrevistados que ao longo de suas vidas estabeleceram com essa rua uma relação de pertencimento e significado. Dessa forma, o objeto de estudo em questão foi trabalhado à luz do conceito de lugar a partir de sua multiplicidade de sentido e significado, como local de passagem para alguns, mas também espaço de encontro, socialização e de tranquilidade para outros, que experienciaram momentos importantes e se utilizaram desse espaço para suas práticas cotidianas.

A Rua do Lazer, também denominada Rua 08, está localizada na região Central da cidade de Goiânia, conhecida também como centro ou núcleo pioneiro da cidade. Essa área foi a primeira a existir e a ser habitada em Goiânia (SILVA, 2006). Tal rua foi inaugurada, segundo matéria publicada no jornal O Popular (ABREU, 2019), no dia 24 de 
| Rua do Lazer no Centro de Goiânia: uma análise a partir do conceito de lugar |

|Josiane Silva de Oliveira | Juliana Mendes de Morais | Marcos Pedro da Silva|

outubro de 1975. Dois anos mais tarde, em 1977, em um período de festa e euforia provocado pelo aniversário da cidade, passou a ser chamada de Rua do Lazer, nome que ainda permanece. De acordo com a Figura 1, ela se situa entre a Avenida Anhanguera e a Rua 03 e, além da circulação constante de pessoas, principalmente durante a semana, em horário comercial, a rua representa a memória afetiva dos moradores, dos comerciantes e de diferentes sujeitos que de alguma forma viveram este e neste lugar.

Segundo o Jornal O Popular (GOIÁS, 1977), em número obtido durante pesquisa documental realizada no Arquivo Histórico Estadual de Goiás, a prefeitura de Goiânia, nessa época, estava realizando diversos projetos, dentre os quais destaca-se os pertencentes à área do lazer. Assim, na administração de Francisco de Castro, diversas praças públicas foram construídas e uma delas foi a Praça do Lazer, na Avenida Anhanguera, período em que a rua foi batizada e ganhou o apelido carinhoso de Rua do Lazer.

Figura 1 - Mapa da localização da Rua do Lazer

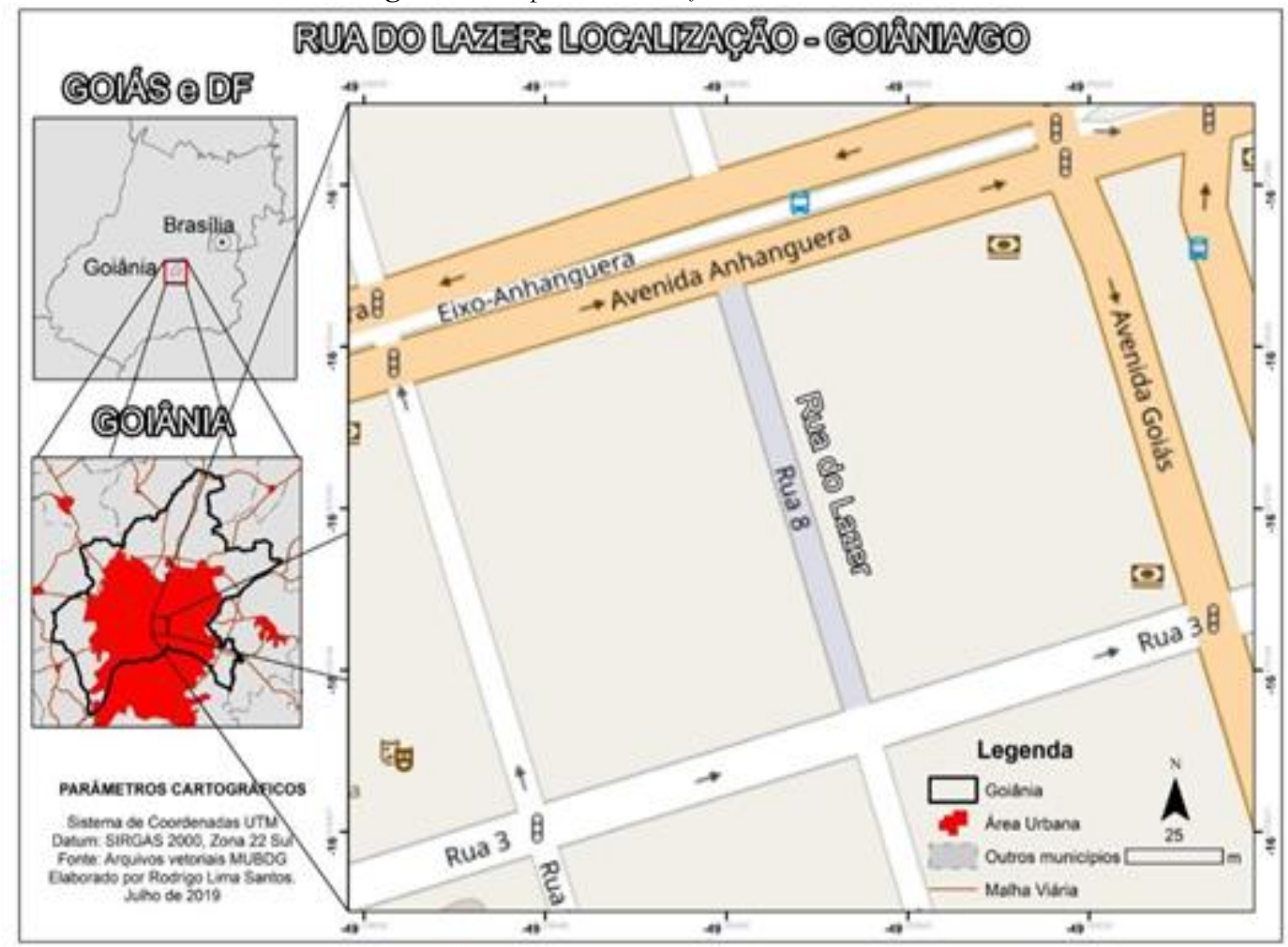

Fonte: Arquivos vetoriais MUBDG (2019).

O interesse em estudar essa rua se justifica por ser ela uma das poucas em todo o centro de Goiânia destinada única e exclusivamente ao trânsito de pedestre, bem como pelo desejo de resgatar as memórias dos sujeitos que ali estabeleceram uma história. Para tal, a categoria lugar será importante para a compreensão da inserção dessa rua na produção 
| Rua do Lazer no Centro de Goiânia: uma análise a partir do conceito de lugar |

|Josiane Silva de Oliveira | Juliana Mendes de Morais | Marcos Pedro da Silva|

do espaço urbano, no que se refere à produção da vida cotidiana na cidade, compreendendo também a sua dinamicidade no que se refere à circulação de pessoas e objetos ao longo dos anos da existência dessa rua (CAVALCANTI, 2001).

Dentre os questionamentos levantados para o desenvolvimento da pesquisa foram elencados: a) qual é o significado de lugar atribuído à Rua do Lazer pelos comerciantes? b) Quais perspectivas o projeto de revitalização da Rua do Lazer traz para os comerciantes que nela vivem há mais tempo?

No sentido de compreender tais questionamentos optou-se, como caminho metodológico, pela pesquisa qualitativa, constituída por análise bibliográfica, documental, observação e realização de entrevistas em campo. Dessa forma, a pesquisa foi realizada ao longo do primeiro semestre de 2019 com as seguintes etapas: observação da rua em diferentes momentos do dia e da semana; pesquisa bibliográfica e documental em órgãos oficiais do estado e entrevistas com três comerciantes, sendo eles os mais antigos da rua. A abordagem qualitativa se mostrou a mais adequada para o propósito da pesquisa ao permitir um contato mais próximo com os sujeitos que vivenciaram as mais diferentes épocas e situações da Rua do Lazer, confrontando esses dados com as pesquisas documentais realizadas e com os aspectos observados pelos pesquisadores.

Com o início das observações da rua notou-se que ela passaria por um processo de revitalização por meio de um projeto acompanhado e executado pela Secretaria Municipal de Planejamento e Habitação (Seplanh), em parceria com uma empresa privada. A obra foi iniciada no mês de abril de 2019, finalizada e inaugurada em outubro desse mesmo ano, em meio às festividades do aniversário de 86 anos da cidade de Goiânia. Posteriormente, no início do ano de 2020, mais uma observação foi realizada na rua, pois o processo de revitalização já havia sido finalizado e era necessário verificar o resultado dessa ação. Assim, foi possível notar mudanças em relação ao calçamento, aos becos e as trocas dos bancos da rua.

Nesse sentido, a discussão sobre a temática abordada utilizou como aporte teórico autores como Carlos (1996), Silva (2006), Rosa (2008) e Serpa (2017), que contribuem para a compreensão da cidade, do espaço urbano e do lugar. Em relação à história oral e às narrativas dos sujeitos referentes à Rua do Lazer, foram utilizados Thompson (1992) e Bosi (1987), Costa (1993), Meihy (1996), Portelli (2016) e Abreu (2017).

Desse modo, o artigo está organizado da seguinte forma: no primeiro momento, são apresentadas as considerações iniciais da pesquisa e a sua localização na Metrópole Goianiense; já no segundo, são abordadas as memórias da rua na perspectiva dos sujeitos 
| Rua do Lazer no Centro de Goiânia: uma análise a partir do conceito de lugar |

|Josiane Silva de Oliveira | Juliana Mendes de Morais | Marcos Pedro da Silva|

entrevistados e o projeto de revitalização como possibilidade de resgate histórico do lugar sob a perspectiva dos comerciantes mais antigos.

\section{A RUA DO LAZER E A MEMÓRIA DO LUGAR NA CIDADE DE GOIÂNIA- GO}

$\mathrm{Na}$ Geografia, o conceito de lugar vem sendo discutido por diferentes paradigmas. Em alguns momentos, trabalhado através da apropriação do capital, sob um viés marxista de competição entre os lugares, em outros, sob uma perspectiva fenomenológica e humanista, entendendo o lugar como espaço da vida, do vivido (SERPA, 2017).

Para Carlos (1996, p. 20), o lugar é uma "porção do espaço apropriável para a vida, apropriada através do corpo, dos sentidos, dos passos de seus moradores, é o bairro, é a praça, é a rua". Ele só pode ser compreendido em suas referências, que não são específicas de uma função ou de uma forma, mas produzidas por um conjunto de sentidos, impressos pelo uso. Nessa linha de pensamento, a autora acrescenta que:

[s]ão os lugares que o homem habita dentro da cidade que dizem respeito ao seu cotidiano e a seu modo de vida onde se locomove, trabalha, passeia, flana, isto é, pelas formas através das quais o homem se apropria e que vão ganhando o significado dado pelo uso. [...] São a rua, a praça, o bairro, espaços do vivido, apropriados através do corpo, espaços públicos divididos entre zonas de veículo e a calçada de pedestre dizem respeito ao passo e a um ritmo que é humano e que pode fugir ao tempo da técnica (CARLOS, 1996, p. 20).

Nesse sentido, é importante resgatar a história dessa rua no contexto da produção do espaço urbano goianiense, pois, embora seja considerada uma cidade jovem, a metrópole de Goiânia traz em seu passado vários lugares materializados na esfera concreta, mas também combinada com um conjunto de componentes simbólicos diluídos na prática social dos sujeitos que a habitam, vivem, transitam ou trabalham nesse mosaico citadino, estabelecendo vínculos de afetividade e identidade com esses lugares. A Rua 08, apelidada de Rua do Lazer por aqueles que a vivenciaram outrora, trata-se de um desses espaços e é marcada pela sua potencialidade de memória do lugar no contexto histórico de formação da área central da cidade.

Refazer o caminho do passado dessa rua por intermédio da história oral torna-se um elemento primordial para entender seu sentido na vida dos sujeitos e sua inserção no contexto da cidade. Cabe destacar que "a busca da identidade dos lugares, tão alardeada nos dias de hoje, tem sido fundamentalmente uma busca de raízes, uma busca de passado" 
| Rua do Lazer no Centro de Goiânia: uma análise a partir do conceito de lugar |

|Josiane Silva de Oliveira | Juliana Mendes de Morais | Marcos Pedro da Silva|

(ABREU, 2017, p. 2). Assim, a partir da história oral é possível realizar um delineamento sobre a rua e seu passado enquanto lugar, seus sujeitos e sua identidade.

Ao abordar a narrativa individual dos sujeitos que convivem na e com a Rua do Lazer, detecta-se que "o lugar em que a memória é elaborada é a mente do indivíduo, e a maneira pelo qual a acessamos é a narrativa individual. Sendo assim, os narradores assumem uma responsabilidade cada vez que relatam sua história" (PORTELLI, 2016, p. 20). Nessa linha de raciocínio, a memória individual pode contribuir, portanto, para a recuperação da memória das cidades.

A partir dela, ou de seus registros, pode-se enveredar pelas lembranças das pessoas e atingir momentos urbanos que já passaram, bem como formas espaciais que já desapareceram. A importância desse resgate para a identidade de um lugar é inquestionável, e é por isso que as "histórias orais" e as "memórias de velhos" vêm hoje se difundindo bastante no Brasil (BOSI, 1987; COSTA, 1993; MEIHY, 1996).

Partindo-se dessas premissas, é possível constatar que "a história oral, então, é história dos eventos, história da memória e história da interpretação dos eventos através da memória. A memória, na verdade, não é um mero depósito de informações, mas um processo contínuo de elaboração e reconstrução de significado" (PORTELLI, 2016, p. 18). Nessa mesma linha de pensamento, ao enfatizar a possibilidade de ser um meio de transformar tanto o conteúdo quanto a finalidade da história, Thompson (1992, p. 22) afirma que:

\footnotetext{
[...] a história oral pode ser utilizada para alterar o enfoque da própria história e revelar novos campos de investigação; pode derrubar barreiras que existam entre professores e alunos, entre gerações, entre instituições educacionais e o mundo exterior, e na produção da história - seja em livros, museus, rádio ou cinema pode devolver as pessoas que fizeram e vivenciaram a história um lugar fundamental, mediante suas próprias palavras (THOMPSON, 1992, p. 22).
}

Dessa forma, a história oral, ao possibilitar que as vozes de diferentes sujeitos sejam conhecidas, escutadas e ouvidas, se configurou como uma metodologia de pesquisa imprescindível para entender e acompanhar o movimento no qual a Rua do Lazer e os entrevistados estão inseridos no espaço-tempo. É importante considerar que "tanto o peso da memória quanto a leveza do esquecimento vão contra o estabelecimento de uma relação crítica e consciente com o passado e com o presente" (PORTELLI, 2016, p. 46). A partir desse contexto, passamos a analisar a Rua do Lazer, sua história, seus sujeitos e suas vozes.

A Figura 2 mostra a Rua do Lazer, que durante muitas décadas coexistia enquanto lugar de encontro, de socialização, de troca e de lazer, se apresentando como um lugar propício para, aos fins de semana, realizar um passeio com a família e os amigos. 


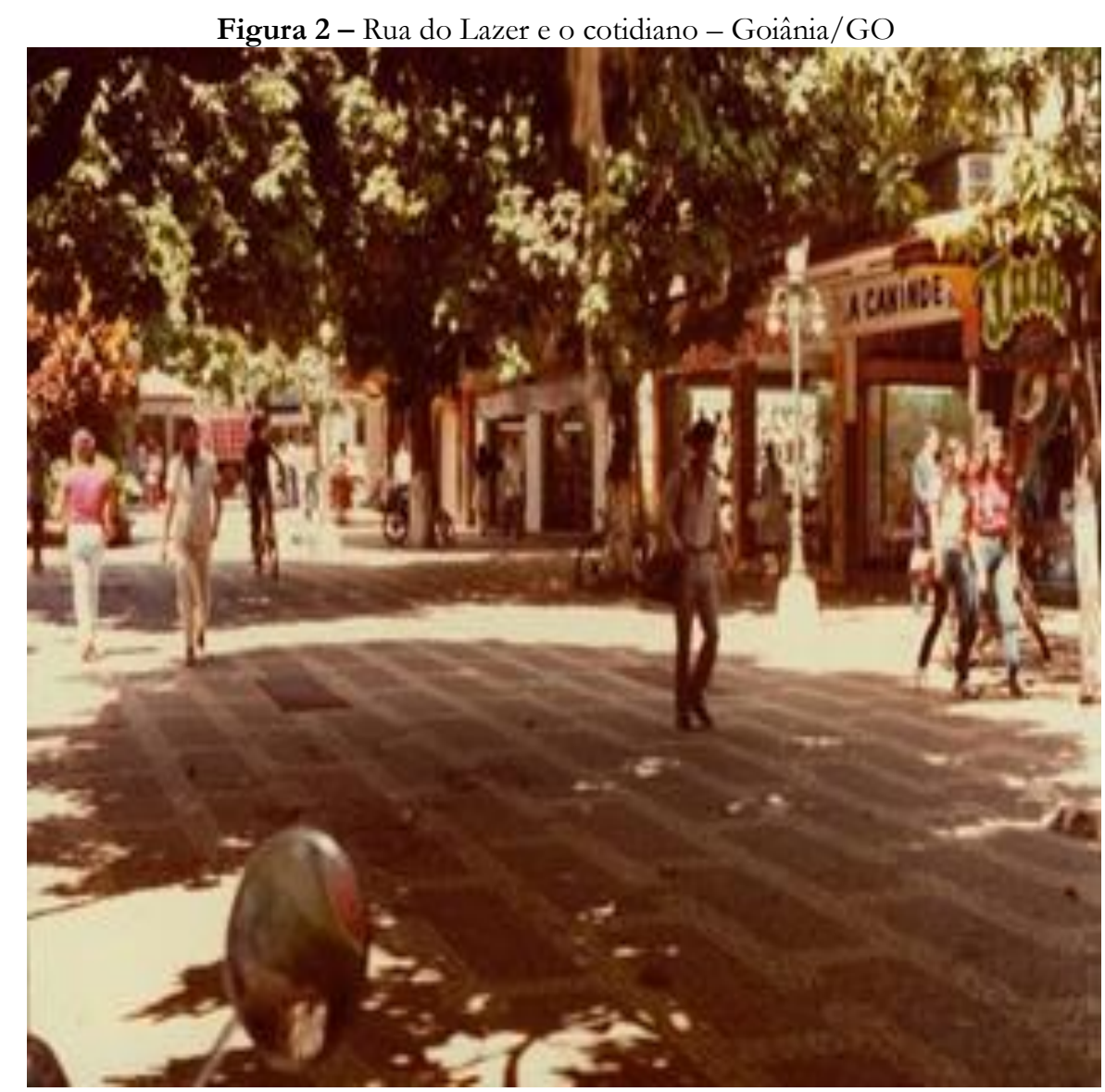

Fonte: Museu da Imagem e do Som - MIS (2019).

Considerando essa época, ao realizar a leitura sobre o lugar é possível observar sua centralidade e influência na relação centro-periferia, seu posicionamento e localização na área central, por concentrar atividades que atraíam os indivíduos de diversas classes sociais, interessados na concentração e prestação de inúmeros serviços, como mostro na Figura 2, a saber, alfaiatarias, lojas de canetas, bares, cinema, teatro. É necessário ressaltar, também, que o centro de Goiânia "foi pensado para cumprir a função principal de reunir a população em eventos cívicos assim como passear, comprar, realizar negócios, trabalhar e morar" (ROSA, 2008, p. 27).

Assim, na busca de revelar a memória desse lugar e seu significado, foram realizadas entrevistas, cujo “[...] principal objetivo não é a busca de informações ou evidências que valham por si mesmas, mas sim fazer um registro 'subjetivo' de como um homem, ou uma mulher, olha para trás e enxerga a própria vida, em sua totalidade, ou em uma de suas partes" (THOMPSON, 1992, p. 258). Nessa perspectiva, elas foram realizadas com comerciantes que atuam nessa rua, em sua maioria desde a década de 1960, e que persistiram às diferentes reconfigurações ocorridas ao longo do tempo, tanto na rua quanto na cidade. Desse modo, têm-se o seguinte perfil: 
| Rua do Lazer no Centro de Goiânia: uma análise a partir do conceito de lugar |

|Josiane Silva de Oliveira | Juliana Mendes de Morais | Marcos Pedro da Silva|

- Entrevistado no 1, masculino, alfaiate, com 52 anos de vivência na rua;

- Entrevistado $n^{\circ}$ 2, masculino, alfaiate, com 39 anos de vivência na rua;

- Entrevistado no 3, masculino, comerciante, com 53 anos de vivência na rua.

Ao ser questionado sobre as lembranças e memórias da Rua do Lazer e o porquê de ela ter esse nome, o primeiro entrevistado narrou que:

\footnotetext{
Porque antes esse trecho aqui passava carro, depois tiraram, fecharam e colou Rua do Lazer. As recordações que eu tenho é que antigamente não se tinha shopping, isso aqui era o shopping. Daqui a Araguaia o povo ia e voltava, tinha o vai e vem. Vai e vem era que os homens ficavam de um lado e outro da rua e as mulheres passando no meio, (gargalhadas), [...] a rua era o shopping de hoje e funcionava até meia-noite. (Entrevistado $\mathrm{n}^{\circ} 1,52$ anos de vivência. Data da entrevista: julho de 2019).
}

$\mathrm{Na}$ fala desse entrevistado há uma colocação importante sobre práticas da época, a exemplo do vai e vem, uma prática de origem francesa denominada footing. Silva (2006) aponta, a partir do pensamento de Oliveira (2003), que tal prática era comum entre os jovens na cidade e ocorria principalmente aos domingos, ao final do término das sessões de cinema. Na década de 1950, os jovens se encontravam na Rua 08, próximo ao Bar Acapulco, ao Lanche Americano e ao Cine Casablanca. Era o típico lazer do período, segundo a afirmação do Entrevistado $n^{\circ} 2$ :

\begin{abstract}
A Rua do Lazer de primeiro tinha movimento, era uma rua para passear mesmo, tinha o cinema "Cine Casablanca", tinha os bares. De primeiro os shoppings [...] eram aqui. Recordação eu tenho do trabalho, do movimento, que era a mesma coisa que o shopping na época, [...] aqui era um movimento danado, tinha umas lojas boas, tinha a Tube, tinha a Magdal, tinha a Sacha. A Magdal está agora lá na Rua 136. [...] isso aqui era o shopping de Goiânia nessa década de 1980. Acabou até ficar fraquinho assim, por causa dos shoppings, o cinema tem muito tempo que acabou. (Entrevistado $\mathrm{n}^{\circ} 2,39$ anos de vivência. Data da entrevista: julho de 2019).
\end{abstract}

Os participantes da pesquisa são comerciantes que viveram, vivem e permanecem na Rua do Lazer há um longo período. Por isso, ao serem questionados sobre as atividades exercidas e o tempo de permanência, a escolha do local para trabalho ou lazer, bem como as pessoas frequentadoras de seus estabelecimentos, o Entrevistado $n^{\circ} 1$ diz estar nessa Rua há 52 anos, relatando que sempre trabalhou como alfaiate, mas que hoje apenas conserta roupas: "antes eu havia começado na Rua 04, mas encontrei esse ponto aqui na Rua do Lazer e passei pra cá". Ainda, diz que na época a rua era frequentada por todos da cidade e por pessoas que moravam no interior do estado.

O segundo entrevistado, também alfaiate, diz que conhece a rua desde 1974 e que passou a trabalhar nela a partir da década de 1980. Ele acrescenta que quem frequentava a 
| Rua do Lazer no Centro de Goiânia: uma análise a partir do conceito de lugar |

|Josiane Silva de Oliveira | Juliana Mendes de Morais | Marcos Pedro da Silva|

rua antigamente era a classe alta da sociedade, mas hoje isso mudou, pois na rua, atualmente, há praticamente o trabalhador, “[...] a pessoa que trabalha que frequenta aqui, quando dá 1 hora tá tudo fechado, vai pro shopping, as lojas eram tudo lotada, não tinha ponto para você comprar fácil não e hoje está tudo fechado”. Dessa forma, um aspecto relevante a ser destacado é que "o centro de Goiânia" foi planejado como uma "zona nobre da cidade" (ROSA, 2008, p. 41).

Por meio das falas dos entrevistados ao descreverem o movimento e as atividades desenvolvidas durante a semana e aos finais de semana na Rua do Lazer, é possível perceber que ela era, na época, o shopping da cidade, concentrando bares, cinema, choperia, lanchonete, shows de grupos musicais como a banda Chorinho. De acordo com o Entrevistado $\mathrm{n}^{\circ} 2$, "esse movimento na rua era toda noite, quando começava a anoitecer o povo vinha todo pra cá, nos finais de semana era a mesma coisa”, e continua:

\footnotetext{
Aqui o movimento de lazer era o cinema e o comércio. No final de semana o movimento era cinema e as feirinhas. Tinha uma feirinha e era lotado de gente. O ponto de Goiânia era aqui. O povo vinha era para cá, igual no Setor Oeste, depois passaram para a Tamandaré. [...] quando tinha esses shows da prefeitura, essas peças de teatro, tinham uns banquinhos $e$ as pessoas ficavam sentadas aí. (Entrevistado $\mathrm{n}^{\circ} 2,39$ anos de vivência. Data da entrevista: julho de 2019).
}

Para os entrevistados, a rua tem um sentido de afetividade, o que justifica a permanência deles durante todos esses anos de vivência, sendo esses comerciantes também os mais antigos. Dessa forma, o Entrevistado $n^{\circ} 1$ realça a importância da rua ao dizer que "[e]ssa rua tem um grande sentido pra mim, tanto é que eu moro aqui na Rua 03, nesse prédio aqui do lado, minha vida toda foi aqui! Essa rua é muito importante pra mim”. Já o segundo entrevistado demonstra que sua afetividade está ligada ao trabalho desenvolvido nesse lugar, que lhe possibilitou criar os filhos e conquistar tudo o que tem hoje. Assim, ele diz:

\begin{abstract}
Eu criei os meus filhos trabalhando aqui, tem 40 anos praticamente, 39 anos que eu estou aqui, fir em julho do ano passado, onde eu adquiri alguma coisa foi aqui. Na época tinha movimento bom, era só eu e outro companheiro de profissão, agora tem muita gente que faz. essa área minha. Ai era lembrança boa, na década de 1980, 1990 era bom, não tinha crise. As lojas eram tudo cheia de gente, hoje não, hoje está tudo danado. Eu fiquei aqui porque a minha clientela era boa e eu ganhei muito dinheiro, eu não tinha concorrência, arrumava umas quatrocentas peças. Eu já cheguei a ganhar uns 20 mil na época, [...] hoje já não ganho tanto. (Entrevistado n ${ }^{\circ}$ 2, 39 anos de vivência. Data da entrevista: julho de 2019).
\end{abstract}

A Rua do Lazer carrega as memórias e as narrativas dos que nela construíram uma história de trabalho e de vida. Por isso, ao serem questionados sobre os fatos e as recordações que mais marcaram suas vidas na Rua do Lazer, é notório, na fala do Entrevistado $\mathrm{n}^{\circ} 3$, o desejo de que outras ruas também seguissem o mesmo padrão dela e 
| Rua do Lazer no Centro de Goiânia: uma análise a partir do conceito de lugar |

|Josiane Silva de Oliveira | Juliana Mendes de Morais | Marcos Pedro da Silva|

fossem destinadas apenas aos pedestres, pois "o que marcou mais foi exatamente deixar de passar veículos, um fator preponderante. Agora o plano inicial era ampliar isso aí, não ficar restrito a essa rua".

Uma das recordações que mais marcaram o Entrevistado $n^{\circ} 1$ se refere à presença e à evidência da homossexualidade na cidade de Goiânia e naquela rua, algo não muito comum na sociedade daquela época. Ele narra o seguinte:

Eu lembrei aqui que vinha um cara, ele era gay, inclusive foi o primeiro gay aqui em Goiânia.
Foi o primeiro que eu conheci, eu não sabia nem o que era isso. O nome dele era [...], quando
ele vinha pra rua o povo jogava pedra nele, o preconceito era grande [...]. Esse era o cara mais
perseguido que se tinha aqui, se eu ver ele eu ainda conbeço, mas não sei nem onde que está. O
que mais me marcou foi esse negócio do [...] que era gay, ele morava fora, então quando ele
entrava na rua, pra mim que sou do interior e não sabia o que era isso, achava uma covardia
o que fazia com ele (Entrevistado $n^{\circ} 1,52$ anos de vivência. Data da entrevista:
julho de 2019).

As percepções mencionadas evidenciam que a Rua do Lazer se constituía como um lugar que identificava e refletia a sociedade goianiense da época, seus hábitos, seus costumes, suas práticas espaciais e o comportamento dos sujeitos que a frequentavam. Contudo, essa situação alterou-se nas décadas seguintes, em razão do crescimento da cidade, da expansão imobiliária, da construção dos condomínios, que contribuíram para que seus frequentadores se direcionassem para áreas mais afastadas do centro e, posteriormente, pela concorrência dos grandes shoppings centers, refletindo na mudança da dinâmica do lugar e nas práticas espaciais de seus sujeitos.

Dessa forma, com o intuito de dar continuidade às discussões expostas, farão parte da análise tratada no tópico a seguir o movimento pelo qual a rua passou ao longo dos tempos e a expectativa dos comerciantes com relação ao processo de revitalização.

\section{PROJETO RE-VIVA: A revitalização como possibilidade de resgate histórico da}

\section{Rua do Lazer enquanto lugar na perspectiva dos comerciantes}

Analisar a Rua do Lazer enquanto lugar inserido em um processo histórico no espaço-tempo requer voltar o olhar para suas características, compreendendo as marcas históricas e as suas resistências no contexto da apropriação, ocupação e produção da vida nesse espaço, mediatizada pelos indivíduos que o produzem, pois, "uma vez que cada sujeito se situa num espaço, o lugar permite pensar o viver, o habitar, o trabalho, o lazer

É importante destacar que quando o entrevistado narra que foi o primeiro gay, isso é na concepção dele.

Omitimos o nome do indivíduo para preservar sua identidade. 
| Rua do Lazer no Centro de Goiânia: uma análise a partir do conceito de lugar |

|Josiane Silva de Oliveira | Juliana Mendes de Morais | Marcos Pedro da Silva |

enquanto situações vividas, revelando, no nível do cotidiano, os conflitos do mundo moderno" (CARLOS, 1996, p. 26).

Nesse sentido, a caracterização atual da Rua do Lazer é marcada por mudanças que ocorreram ao longo do seu processo histórico de produção do espaço urbano de Goiânia, conforme pode ser evidenciado na fala do Entrevistado $n^{\circ} 3$ :

\begin{abstract}
Aqui na esquina era o restaurante Bolonha, um dos bons aqui de Goiânia. Em frente aqui tinha o bar Samburá e a rua ela tinha uma movimentação muito grande. Havia aqui o lanche americano que fez. um sucesso violento, o cine Casablanca, restaurante Acapulco, que depois passou pra Casa do Cabeleireiro, o restaurante Bolonha passou pra Perfumaria Nice e Casa Maroto. Criou-se aqui mais ou menos um centro de perfumaria. (Entrevistado $\mathrm{n}^{\mathrm{o}} 3,53$ anos de vivência. Data da entrevista: julho de 2019).
\end{abstract}

Essa narrativa mostra algumas mudanças em relação às lojas que ali existiam e que foram sendo trocadas por outros estabelecimentos, lojas que existiam antes, mas presentes hoje apenas nas lembranças que permeiam o lugar; entretanto, o mesmo não aconteceu com a Caneta Dourada, como mostram as Figuras 3 e 4.

Figura 03 - Caneta Dourada na década de 1960.

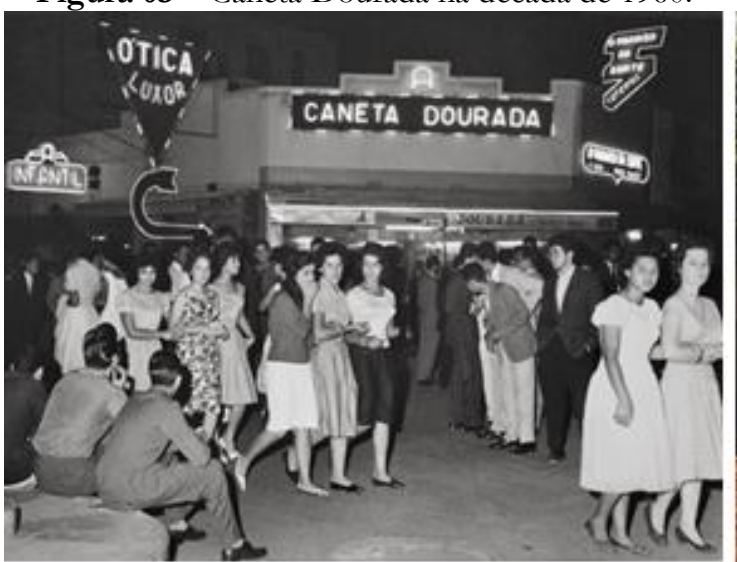

Fonte: Museu da Imagem e do Som (MIS).
Figura 04 - Caneta Dourada atualmente.

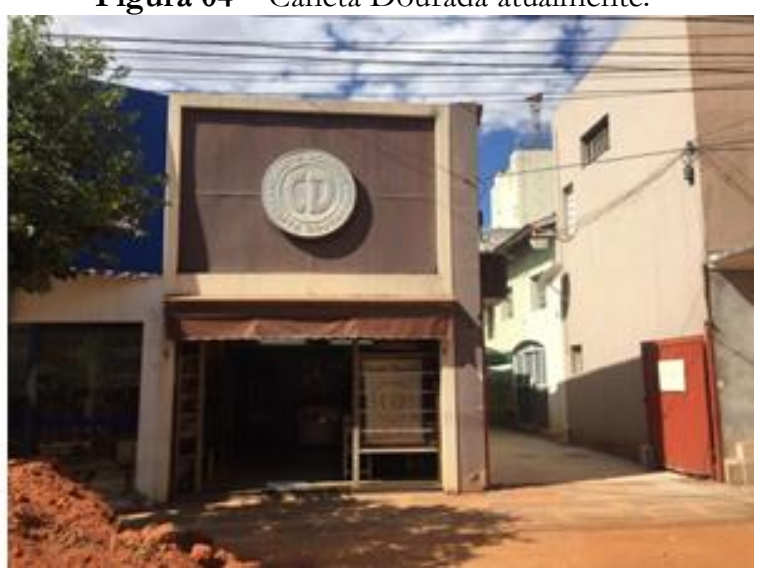

Fonte: Autores (2019).

A foto mostrada na Figura 3 foi tirada na década de 1960, quando a loja estava situada na Avenida Anhanguera com a Rua 07; depois, ela mudou-se para a Rua 08, em 1966, onde permanece até hoje, como se percebe na Figura 4. Sobre a mudança, o Entrevistado $n^{\circ} 3$ relata que "foi um acaso fortuito, a Caneta Dourada era lá em frente ao Café Central, lá foi vendido, aí eu tinha que sair de lá, achei esse ponto aqui e comprei”. Ele explica:

A loja aqui era frequentada por pessoa proeminente daqui, entre eles Juruema de Guimarães, ele era jornalista, foi diretor da Assembleia Legislativa, escrevia muito bem e vinha aqui todos os dias depois de aposentado, e aqui todos os dias vinha os amigos dele bater papo aqui. Era mais ou menos uma média de uns cinco acima de 80 anos. [...] Eu tenho uma foto aqui que foi batida quando o Chiquim de Castro era prefeito e esteve aqui, foi na gestão dele que foi 
| Rua do Lazer no Centro de Goiânia: uma análise a partir do conceito de lugar |

|Josiane Silva de Oliveira | Juliana Mendes de Morais | Marcos Pedro da Silva |

aceita a transformação, e nesse dia aqui ele estava justamente visitando pra saber o interesse que nós têm em transformar a Rua em Rua do Lazer. (Entrevistado n 3, 53 anos de vivência. Data da entrevista: julho de 2019).

Tal loja se constitui em elemento importante de resistência ao processo de modernização, inserida na perspectiva não só comercial, mas também nas relações de vivência nesse lugar, relevância evidenciada na afirmação do proprietário da loja e sujeito com mais tempo de vivência na rua. Ele afirma que "a Caneta Dourada era conhecida na cidade inteira, a única especializada em canetas, então todo lugar que você ia, aqui não tem, mas na Caneta Dourada tem”. Assim, os serviços que não eram encontrados em outros estabelecimentos referentes à especialidade da loja eram encontrados na Caneta Dourada, por isso ela era referência na cidade.

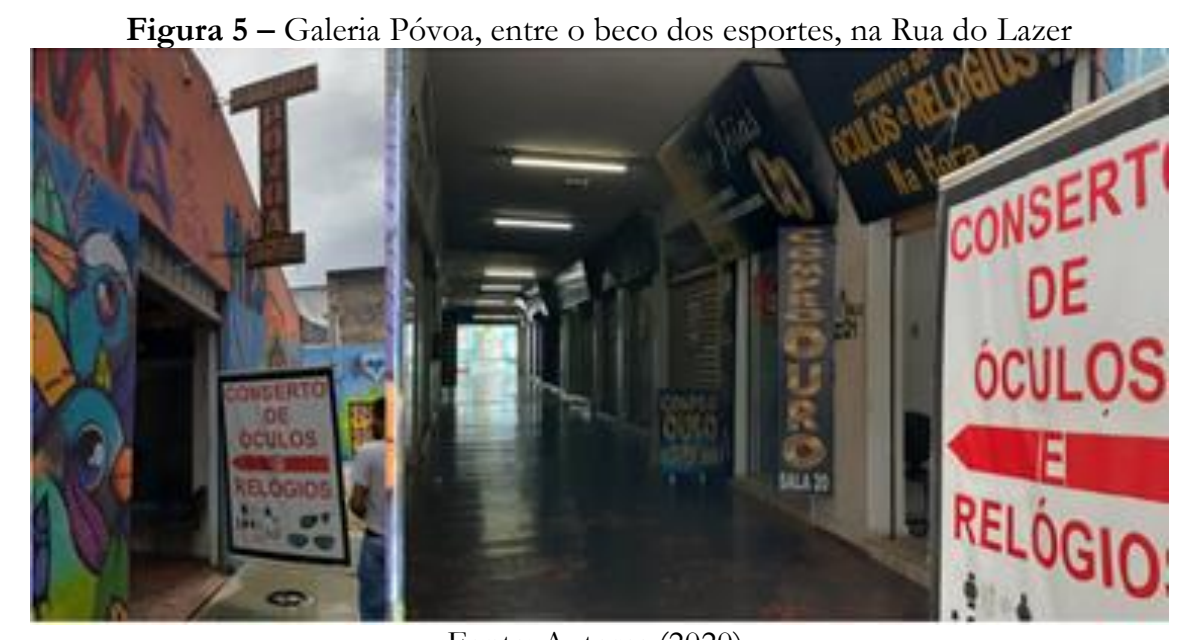

Fonte: Autores (2020).

Considerando as décadas passadas, especificamente até 1980, antes do surgimento do primeiro shopping de Goiânia, ${ }^{3}$ o comércio na Rua Lazer estava ligado ao varejo durante a semana, por meio das diversas lojas, feiras, cinemas, shows, bares e choperias durante a noite e aos fins de semana. Entretanto, a expansão urbana deixou suas marcas e, com isso, o comércio local passou por diversas transformações, com a presença de lojas de telefonia móvel, financeira, lotérica, produtos naturais, perdendo espaço de centralidade. Prova disso é que das vinte e uma lojas da Galeria Póvoa somente oito estão abertas, como mostra a Figura 5.

Assim, os bares e as choperias que também marcaram as memórias daqueles que frequentam a rua há mais tempo não fazem parte de sua atual forma, assim como ocorreu com o Cine Casablanca, demonstrando que a reorganização socioeconômica não atingiu

3 Segundo Silva (2006), o Shopping Flamboyant foi construído na década de 1980, no Jardim Goiás; já na década de 1990 são construídos os shoppings Bougainville, no Setor Marista, e o Goiânia Shopping, no Setor Bueno, para citar os mais antigos da cidade. 
somente o comércio tradicional varejista e as feirinhas, mas também aqueles voltados para a cultura e o lazer. Nessa direção:

\begin{abstract}
No plano do lugar, a extensão do espaço revela novas formas, funções e estruturas sem que as antigas tenham, necessariamente, desaparecido. Esse fato aponta uma contradição importante entre as persistências - o que resiste e se reafirma continuamente enquanto referencial da vida - e o que aparece como “novo", pela adoção do processo de modernização (CARLOS, 2011, p. 83).
\end{abstract}

Tendo em vista que ao longo do tempo o centro das cidades passou por diversas transformações que ocasionaram mudanças nas formas de ocupação da zona urbana, "atualmente a área central das cidades, local a partir do qual se configuram novos espaços, está vivenciando um processo denominado revitalização urbana.” Foi por esse processo que o centro de Goiânia, com destaque para a Rua do Lazer, passou; o projeto de revitalização, segundo o segundo o G1 Goiás (2019), vem com o objetivo de devolver a Rua àquilo que era antes.

Segundo Moraes (2019), o principal objetivo do projeto é a revitalização urbanística e paisagística de áreas que compõem o traçado histórico da capital goianiense. Desse modo, a Secretaria Municipal de Planejamento e Habitação (Seplanh) acompanhou e executou o processo, em parceria com uma empresa privada, "como permuta junto ao Projeto" Diferenciado de Urbanização - PDU” (GOIÂNIA, 2019, p. 25).

Por isso, um aspecto importante a ser mencionado refere-se ao processo de revitalização inserido no Projeto Re-Viva ${ }^{5}$ Goiânia, conforme mostra a Figura 6 a seguir: As obras foram iniciadas no dia 15 de abril de 2019 e no dia da primeira observação in loco nos deparamos com o processo de desmontagem de alguns equipamentos que ali estavam, como bancos, luminárias, orelhões, com lixos e entulhos acumulados nos becos, por isso as perspectivas de melhoras com relação aos impactos da obra sobre a rua foram analisadas também a partir das narrativas dos sujeitos entrevistados.

4 O Projeto Diferenciado de Urbanização - PDU, Lei n. 8.767, de 19 de janeiro de 2009, regulamenta a Lei Complementar $n^{\circ} 171$, de 29 de maio de 2007, e o artigo $9^{\circ}$ da Lei Complementar de $n^{\circ} 181$, de $1^{\circ}$ de outubro de 2008. O PDU caracteriza-se pelo "ordenamento e ocupação dos Vazios e Lotes Vagos" da cidade de Goiânia (GOIÂNIA, 2009).

5 Esse projeto foi elaborado pela Secretaria Estadual do Meio Ambiente e dos Recursos Hídricos, Cidades, Infraestrutura e Assuntos Metropolitanos (Secima) e, posteriormente, doado à Prefeitura Municipal de Goiânia (ABREU, 2019). 
| Rua do Lazer no Centro de Goiânia: uma análise a partir do conceito de lugar |

|Josiane Silva de Oliveira | Juliana Mendes de Morais | Marcos Pedro da Silva |

Figura 6 - Rua do Lazer antes (a), durante (b) e depois da revitalização (c) respectivamente

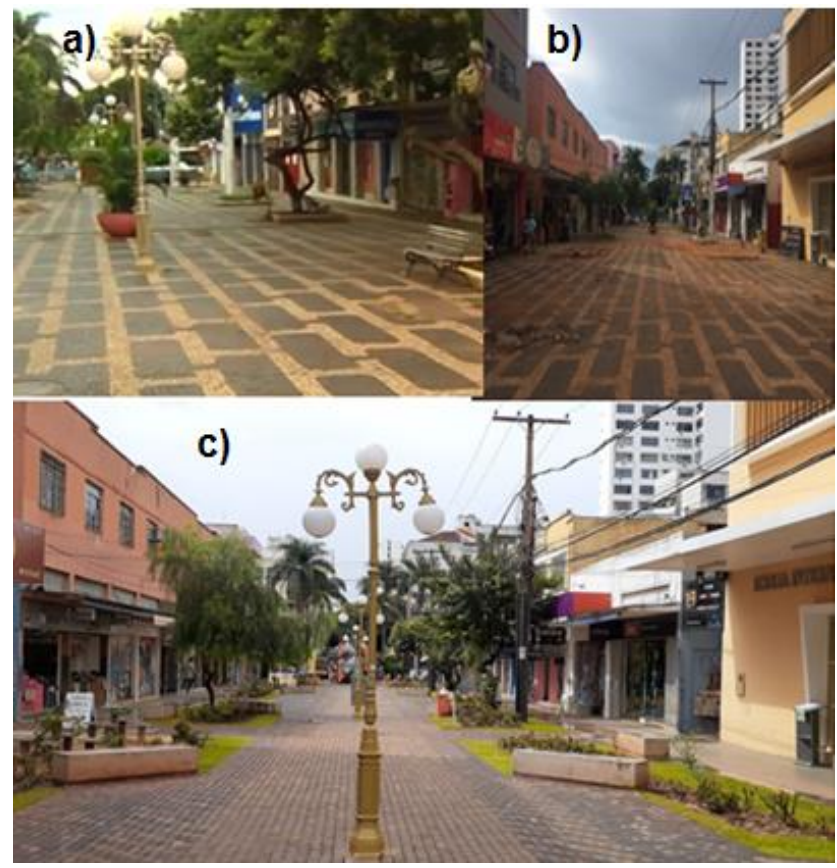

Fonte: G1 Goiás e acervo dos Autores (2020).

A inauguração da Rua do Lazer aconteceu no dia 19 de outubro de 2019, entre as comemorações do aniversário da cidade de Goiânia, com aproximadamente 70 dias de atraso, de acordo com o projeto inicial (CARNEIRO, 2019). Cabe destacar que, ao término da reforma, muitos desses elementos - características marcantes da Rua - não retornaram a sua configuração atual, a exemplo dos bancos de madeira, substituídos por bancos de concreto, como exemplifica a Figura 6.

Figura 7 - Becos da Rua do Lazer durante (a) e após a revitalização (b), com os elementos que o

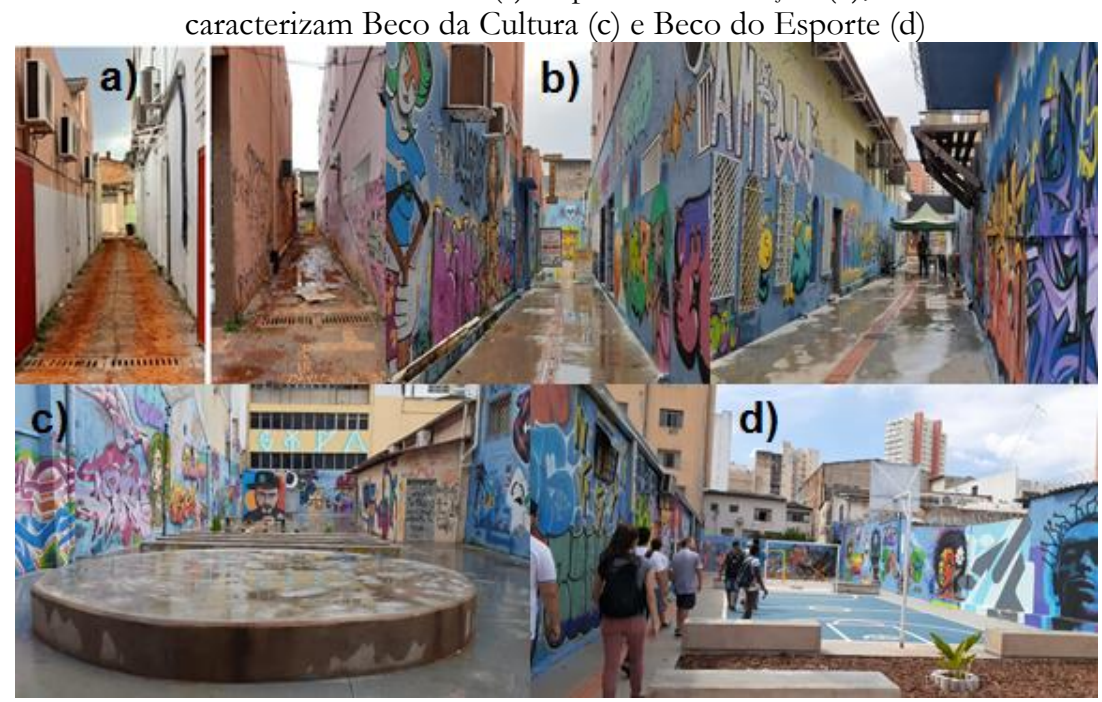

Fonte: Acervo dos autores (2019/2020).

A rua também apresenta, em sua configuração, dois becos, um chamado Beco da Cultura e o outro, Beco do Esporte. De acordo com Abreu (2019), os becos presentes na 
| Rua do Lazer no Centro de Goiânia: uma análise a partir do conceito de lugar |

|Josiane Silva de Oliveira | Juliana Mendes de Morais | Marcos Pedro da Silva |

Rua do Lazer (Figura 7) também foram revitalizados e neles se encontram, atualmente, o Teatro Carlos Moreira e uma quadra com parquinho, respectivamente. A Rua do Lazer está localizada em uma área denominada de núcleo pioneiro da cidade, contudo, vale ressaltar que não há nela nenhum edifício tombado como patrimônio histórico da cidade de Goiânia.

Ao analisar o projeto de revitalização, é preciso considerar o processo de produção do espaço urbano da cidade e inserir, nessa discussão, a finalidade e a função do Setor Central para a cidade de Goiânia, que até a década de 1970 apresentava regiões definidas quanto ao uso, no que se refere à “[...] administração (Praça Cívica), bancos e hotéis (Praça do Bandeirante), escritórios e residências (ao longo da Avenida Goiás), diversas lojas e cinemas (ao longo da Avenida Anhanguera e Rua 4)", além da centralidade de Campinas (ROSA, 2008, p. 42).

Com o passar das décadas, várias transformações ocorreram, com reflexos no processo de uso e apropriação do espaço urbano, direcionados à expansão da cidade na produção de outros espaços destinados à moradia, à indústria, ao lazer, bem como a outros serviços. Nesse sentido, observa-se uma contradição "entre a produção de um espaço orientada pelas necessidades econômicas e políticas (em suas alianças possíveis), e a reprodução do espaço enquanto condição, meio e produto da reprodução da vida social" (CARLOS, 2011, p. 72).

Dessa forma, quando questionado sobre a expectativa em relação ao processo de revitalização da Rua do Lazer, o Entrevistado $n^{\circ} 1$ se mostrou esperançoso quanto aos seus benefícios de melhoria ao relatar: "tanto é que eu vou arrumar minha loja, vou reformar ela, as pessoas vão frequentar mais, e eu acho também que o movimento vai aumentar muito, vai voltar tudo". Entretanto, para que a revitalização urbana ocorra efetivamente é necessário planejamento detalhado, levando em "consideração o ambiente existente, respeito ao entorno, estudos de ocupação para uso misto, criação de agentes catalisadores e de uma boa imagem, gestão contínua e participação de várias esferas” (GASPAR et al., 2017, p. 188).

Para o Entrevistado $n^{\circ} 3$ a perspectiva é divergente. Sua fala mostra um olhar de descrença quanto à revitalização. Isso porque, em sua concepção, seria preciso “[...] trazer gente para o centro, e não se traz facilmente, aqui a única maneira de trazer gente para o centro é exatamente incentivar a construção civil de moradias". Acrescenta:

Se isso aqui estivesse cheio de edifícios, por exemplo, você morando aqui no centro você não precisa de carro aqui pra nada, a não ser que você queira ir para grandes distâncias, ainda mais com escola perto. [...] se aqui tivesse gente morando e que tem filhos, você teria que sair do 
| Rua do Lazer no Centro de Goiânia: uma análise a partir do conceito de lugar |

|Josiane Silva de Oliveira | Juliana Mendes de Morais | Marcos Pedro da Silva |

seu prédio e levar a criança para passear, e acaba comprando. Uma coisa puxa a outra. (Entrevistado no 3, 53 anos de vivência. Data da entrevista: julho de 2019).

Partindo desse ponto de vista, fica evidente que não basta somente promover melhorias na estrutura física da rua. Para esse entrevistado, o Setor Central não é mais uma opção de moradia de grande parte da população e está esvaziado. Ele afirma: “[...] como resultado aqui não povoou, se tivesse feito aqui como fizeram lá no Bueno, com aquele espigão de tudo quanto é lado... que adianta embelezar, se não tem gente?”. Nesse sentido, o entrevistado coloca a necessidade de moradias como forma de trazer as pessoas para que elas possam usufruir do centro, uma vez que “[s]ão as relações que criam os 'sentidos' dos lugares da metrópole. Isto por que o lugar só pode ser compreendido em suas referências, que não são específicas de uma função ou de uma forma, mas produzidas por um conjunto de sentidos, impressos pelo uso" (CARLOS, 1996, p. 22).

A região central de Goiânia, com destaque para a Rua do Lazer por estar inserida nessa localidade, pode ser definido, desde seu início, como um espaço de grande importância para a população goianiense, já que foi a partir dessa área que a cidade surgiu, compreendida como a própria "cidade", abrigando funções relevantes, sobretudo o comércio, e representando, também, o convívio da população, pois somente a partir de 1975 foi que de fato se iniciou seu processo de expansão (REZENDE, 2019, p. 25).

Dessa forma, torna-se oportuno ressaltar que, embora as dinâmicas do espaço tenham sido alteradas, a rua e seus sujeitos ainda são referência na área central. Ela permanece como identidade histórica e espacial para os comerciantes ligados a esse lugar, que se reconhecem, pois nela construíram as suas trajetórias de vida, uma vez que a rua, enquanto lugar, "[...] guarda em si, e não fora dele, o seu significado" (CARLOS, 1996, p. $30)$.

\section{CONSIDERAÇÕES FINAIS}

Ao estudar o lugar tomando como referência a Rua do Lazer a partir da história oral por meio da memória urbana dos comerciantes mais antigos, conclui-se que o passado ficou registrado naquela rua por meio das narrativas, das formas, das trajetórias e das histórias interligadas entre os sujeitos que compartilham e vivenciam esse lugar. A partir dos depoimentos relatados, constata-se que escutar as memórias dos sujeitos é entender que elas estão em constante processo de elaboração e reconstrução dos significados dos eventos do vivido. 
| Rua do Lazer no Centro de Goiânia: uma análise a partir do conceito de lugar |

| Josiane Silva de Oliveira | Juliana Mendes de Morais | Marcos Pedro da Silva |

Portanto, pensar a Rua do Lazer enquanto lugar e seus sujeitos requer, também, transitar entre o passado e o presente para realizar a leitura do cenário atual, que também envolve o processo de revitalização, pensado no desenvolvimento deste trabalho sob a perspectiva dos entrevistados. Para alguns, a revitalização será positiva, visto ser ainda recente. Já para outros, é necessário muito mais que um projeto de melhoria da estrutura física da rua.

Enfim, longe de esgotar as possibilidades de análise sobre a Rua do Lazer, buscouse trazer alguns apontamentos a respeito das memórias do lugar, narradas por seus sujeitos considerando o movimento no espaço-tempo. A partir disso, o projeto de revitalização pode trazer um novo valor atribuído à Rua do Lazer que, diante do acelerado crescimento das cidades médias e grandes, viram o centro esvaziar-se; por isso é importante a revalorização atual do passado gerada pela constante memória dos lugares, que são também memórias da cidade.

\section{REFERÊNCIAS}

ABREU, Maurício de. Sobre a memória das cidades. In: CARLOS, Ana Fani Alessandri; SOUZA, Marcelo Lopes de; SPOSITO, Maria Encarnação Beltrão (Org.). A produção do espaço urbano: agentes e processos, escalas e desafios. São Paulo: Contexto, 2017. p. 1939.

ABREU, Vandré. Rua do Lazer será revitalizada. Jornal O Popular, Cidades, 6 de janeiro de 2019. Disponível em: < https://www.opopular.com.br/noticias/cidades/rua-do-lazerserá-revitalizada-1.1699774>. Acesso em: 18 jul. 2019.

BOSI, Ecléa. Memória e sociedade: lembrança de velhos. São Paulo: T. A. Queiroz/Edusp, 1987.

CARLOS, Ana Fani Alessandri. Da organização à produção do espaço. In: CARLOS, Ana Fani Alessandri. A condição espacial. São Paulo: Editora contexto, 2011. p. 63-88.

CARLOS, Ana Fani Alessandri. O lugar no/do mundo. São Paulo: Ed. Hucitec, 1996.

CARNEIRO, Mariana. Rua do Lazer, no Centro de Goiânia, deve ser inaugurada dia 19. Jornal O Popular, Cidades, 02 out. 2019. Disponível em: $<$ https://www.opopular.com.br/noticias/cidades/rua-do-lazer-no-centro-degoi \%C3\%A2nia-deve-ser-inaugurada-dia-19-1.1900111>. Acesso em: 15 mar. 2020.

CAVALCANTI, Lana de Souza. Uma geografia da cidade - elementos da produção do espaço urbano. In: CAVALCANTI, Lana de Souza (Org.). Geografia da cidade: a produção do espaço urbano de Goiânia. Goiânia: Editora Alternativa, 2001. p. 11-32.

COSTA, Rosalina Maria. Em busca do espaço perdido: a reconstrução das identidades espaciais do bairro da Lapa na cidade do Rio de Janeiro. 1993. Dissertação (Mestrado em 
| Rua do Lazer no Centro de Goiânia: uma análise a partir do conceito de lugar |

|Josiane Silva de Oliveira | Juliana Mendes de Morais | Marcos Pedro da Silva |

Geografia) - Instituto de Geociências, Universidade Federal do Rio de Janeiro, Rio de Janeiro, 1993.

GASPAR, Jadhi Vincki [et al.]. A revitalização de espaços urbanos: o caso do Centro Sapiens em Florianópolis. Revista Livre de Sustentabilidade e Empreendedorismo, v. 2, n. 4, p. 183-205, out./dez. 2017.

GOIÁS, Arquivo Histórico Estadual de. O Popular. Projetos realizados na prefeitura de Goiânia. Outubro de 1977.

GOIÂNIA. Lei $\mathbf{n}^{\mathbf{0}} \mathbf{8 . 7 6 7}$, de 19 de janeiro de 2009. Regulamenta o art. 119, da Lei Complementar $\mathrm{n}^{\circ} .171$, de 29 de maio de 2007 e art. $9^{\circ}$, da Lei Complementar no. 181, de $1^{\circ}$ de outubro de 2008, que Dispõe sobre Projeto Diferenciado de Urbanização. Disponível em:

<https://www.goiania.go.gov.br/html/gabinete civil/sileg/dados/legis/2009/lo 2009011 9 000008767.html>. Acesso em: 22 fev. 2021.

MEIHY, José Carlos Sebe Bom. Manual de história oral. São Paulo: Loyola, 1996.

MORAES, Catherine. Prefeitura dá início à revitalização da Rua do Lazer no Centro de Goiânia; veja vídeo. Jornal O Popular, Cidades, 15 abr. 2019. Disponível em: $<$ https://www.opopular.com.br/noticias/cidades/prefeitura-d $\% \mathrm{C} 3 \% \mathrm{~A} 1$-in $\% \mathrm{C} 3 \%$ ADcio$\% \mathrm{C} 3 \% \mathrm{~A} 0$-revitaliza $\% \mathrm{C} 3 \% \mathrm{~A} 7 \% \mathrm{C} 3 \% \mathrm{~A} 3 \mathrm{o}$-da-rua-do-lazer-no-centro-de-goi $\% \mathrm{C} 3 \% \mathrm{~A} 2$ niaveja-v $\%$ C3\%ADdeo-1.1776460>. Acesso em: 21 maio 2019.

OLIVEIRA, Eliézer Cardoso. História Cultural de Goiânia. Goiânia: Editora Alternativa, 2003.

PORTELLI, Alessandro. História oral como arte da escuta. Tradução de Ricardo Santhiago. São Paulo: Letra e Voz, 2016.

REZENDE, Sandra Catharinne Pantaleão. Expansão e fragmentação do território: Goiânia de cidade planejada à metrópole regional. Desenvolvimento Regional em debate DVB, v. 9, ed. esp., p. 22-42, maio 2019.

ROSA, Alda Maria Araújo Torreal. Jardim Goiás: uma nova área de centralidade em Goiânia. 2008. 123 f. Dissertação (Mestrado em Geografia) - Universidade Federal de Goiás (UFG), Goiânia, 2008.

SERPA, Angelo. Lugar e centralidade em um contexto metropolitano. In: CARLOS, Ana Fani Alessandri; SOUZA, Marcelo Lopes de; SPOSITO, Maria Encarnação Beltrão (Org.). A produção do espaço urbano: agentes e processos, escalas e desafios. São Paulo: Contexto, 2017. p. 97-108.

SILVA, Ciro Augusto de Oliveira e. Revitalização e preservação do patrimônio arquitetônico e urbanístico do centro de Goiânia. 2006. 211 f. Dissertação (Mestrado Profissional em Gestão do Patrimônio Cultural) - Universidade Católica de Goiás (PUC), Goiânia, 2006.

THOMPSON, Paul. A voz do passado. Tradução de Lólio Lourenço de Oliveira. Rio de Janeiro: Paz e Terra, 1992. 
| Rua do Lazer no Centro de Goiânia: uma análise a partir do conceito de lugar|

|Josiane Silva de Oliveira | Juliana Mendes de Morais | Marcos Pedro da Silva|

\section{Como citar:}

\section{ABNT}

OLIVEIRA, J. S.; MORAIS, J. M.; SILVA, M. P. Rua do Lazer no Centro de Goiânia: uma análise a partir do conceito de lugar. InterEspaço: Revista de Geografia e Interdisciplinaridade, v. 7, e202122, 2021. Disponível em: <http://dx.doi.org/10.18764/2446-6549.e202122>. Acesso em: 22 ago. 2021.

\section{APA}

Oliveira, J. S., Morais, J. M., \& Silva, M. P. Rua do Lazer no Centro de Goiânia: uma análise a partir do conceito de lugar. InterEspaço: Revista de Geografia e Interdisciplinaridade, v. 7, e202122. Recuperado em 22 agosto, 2021, de http://dx.doi.org/10.18764/24466549.e202122

\section{@c) creative}

This is an open access article under the CC BY Creative Commons 4.0 license.

Copyright (C) 2021, Universidade Federal do Maranhão.

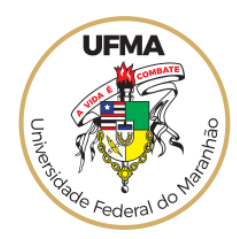

